\title{
1. New themes in institutional analysis: topics and issues from European research
}

\author{
Georg Krücken, Renate E. Meyer and \\ Peter Walgenbach
}

Institutional theory has captured the attention of a wide range of scholars in organizational studies and has become one of the dominant organizational approaches over the past decades. Its roots can be traced to Europe, in particular to the German-speaking countries, leading back to the work of eminent sociological scholars such as Max Weber, Alfred Schütz, Thomas Luckmann, and Peter Berger. Given this legacy, surprisingly enough, it was only in the 1990s that the new institutional theory started to gain ground in the German-speaking countries. While sociological institutionalism had already become a leading paradigm in the English-speaking world (especially in North America) and was also beginning to thrive in Scandinavia (with the SCANCOR - Scandinavian Consortium for Organizational Research - connection to Stanford University), it was regarded somewhat unusual, even 'esoteric' in the German-speaking countries at this time. The few researchers who decided to draw on the perspective were dispersed at different universities and the physical separation together with the diverse research communities they were embedded in, made discussions and exchange of ideas even more difficult. Further, those who worked in the tradition of institutional theory found themselves confronted with the fact that not only were very few colleagues available for discussion and collaboration, but also that the discussions in the circles of the 'uninitiated' were almost exclusively limited to justifying the value of sociological institutionalism and delineating it from other variants of institutional theory, especially economic institutionalism. 


\subsection{COMING HOME}

The initial idea of setting up a German-speaking network of scholars who engaged in institutional theory was born in 2004 at the end of the European Group for Organizational Studies (EGOS) Colloquium in Ljubljana (Slovenia) and implemented shortly afterwards. There was consensus among the founders of the network that a platform that served the dual purpose of providing a means of regularly exchanging ideas and training scholars interested in institutional theory was necessary in the German-speaking countries. The hitherto usual development of junior scholars in the form of doctoral seminars under the guidance of only one professor at a university was identified as insufficient. In order to gain the 'critical mass' needed for a specialized program, it was considered necessary to bring together colleagues and $\mathrm{PhD}$ students from all three countries. Another significant and much less practical driven goal was to reconnect new institutionalism with its sociological origins.

\subsection{GOING INTERNATIONAL}

After the first two workshops in Vienna (Austria), a third one was organized in Bergamo (Italy). Royston Greenwood, a prominent representative of new institutionalism in North America, was invited. He expressed his amusement to find that German-speaking academics were meeting in Italy to discuss in German a theory particularly prominent in North America and encouraged us to open up to English-speaking scholars. In addition, an increasing number of non-German-speaking colleagues from other European countries expressed their interest in joining our group. As a consequence, not only was the fourth workshop organized in English, it also adopted institutionalized practices of international conferences: keynote speakers from Europe and North America were invited and their talks were highlighted in the proceedings of the workshops. We invited (in chronological order, beginning in 2007): Royston Greenwood, Kerstin Sahlin, Marie-Laure Djelic, Mike Lounsbury, Woody Powell, Barbara Czarniawska, Bruce Carruthers, Frank Dobbin, John Meyer, and John Mohr. In addition to the workshop theme, the excellent venues of the meetings (Vienna, Bergamo, Naples, Lyon, Barcelona, Warsaw, Rome, Lucerne, and Jerusalem) also played an important role in attracting these renowned scholars. We would wholeheartedly like to thank the above-mentioned speakers and the local organizers of all our workshops who tremendously contributed to the success and the continued growth of our network. All in all, the switch to English as the main language helped expand the network's 
reach beyond countries other than Austria, Germany and Switzerland (see http://www.newinstitutionalism.org/). The yearly workshops are attended by growing numbers of European as well as international colleagues and $\mathrm{PhD}$ students. Despite this increase in the number of participants, we make every effort to keep the small and informal workshop spirit alive. This edited volume is the outcome of the recent annual meetings and its chapters reflect the breadth and diversity of the work discussed.

\subsection{THEORIES AND METHODOLOGICAL OBJECTIVES}

An important intellectual objective of our network is to examine neoinstitutionalism in North American sociological and organizational theories and (re-)connect them with European research traditions. Researchers from both sides of the Atlantic share this goal and collaborate. Primarily, we see opportunities to expand current knowledge by combining established knowledge and research traditions with more recent theoretical and methodological advances.

From a theoretical point of view, we see untapped opportunities to create strong links with current social theories and social-philosophical foundations as well as close interactions with classical sociology. The North American debates in our field, from our point of view, are too quick to dismiss these linkages as 'meta-theories' or as an 'obsolete body of thought' having no real significance for current research. With regard to these social theories, the discussion of Giddens' theory of structuration, Bourdieu's theory of social fields, and Luhmann's theory of societal differentiation have played a significant role and should continue to inspire institutional thinking. All these theories rely on a differentiated understanding of modern societies that clashes with the strong homogenization assumptions of early neo-institutionalism (Hasse and Krücken, 2008), but anticipate in a broad and elaborate way much of the now thriving discussions on pluralism, complexity, and hybridity. These theories are primarily macro-sociological and allow for a systematic integration of the heterogeneities of modern societies. Moreover, it is critical to take into account the social phenomenology and practice theories in sociology in order to strengthen the micro-sociological and social-philosophical underpinnings of neo-institutional research and theory. Here, it is necessary to relate back to classical theories such as those of Max Weber or Alfred Schütz and the traditions of the sociology of knowledge with contemporary theoretical approaches and methods to arrive at the foundation of agency in institutional theory (Meyer, 2008). This, no doubt, is increasingly important for 
neo-institutionalism: dealing with the fundamental questions underlying various theories avoids reinventing the wheel and allows for differentiating between genuine theoretical advances and mere 'fads and fashions'.

On the methodological level, it is worth pointing out the relevance of qualitative approaches and especially the use of case studies in European neo-institutionalism (Czarniawska and Sevón, 2003; Lounsbury and Beckman, 2015). Case studies are particularly useful for studying local structures. They are also relevant for interpreting overlapping social expectation structures as well as for developing comparative perspectives. However, case studies are by no means the only research method suitable for the study of organizations and ideally should be combined with other methodological approaches. A more recent phenomenon in neoinstitutionalism research is the introduction of mixed-methods approaches that are able to reconstruct meaning structures. These approaches overcome some of the challenges associated with using case studies alone and are even relevant for undertaking larger-scale research studies (e.g., correspondence analysis, qualitative comparative analysis, or semantic network analysis).

Empirically, our research examines a broad range of organizational forms as well as national contexts. A remarkable shift in the focus of empirical research over time can be observed in North American neoinstitutionalism. While in the beginning it was mainly concerned with non-profit and public sector organizations, today the focus is more on the economic sector and its organizations. This shift in research focus has contributed to a broader institutionalization of neo-institutionalism in the North American organizational and management research. Due to the large share of the public sector in most European countries this change is not so distinctly visible in the European context. A cross-sector comparison of different forms of organizations is actively discussed in our network within the context of various national frameworks along with subsequent possibilities for comparative analyses. Discussions, for example, regularly deal with 'varieties of capitalism', an issue widely discussed in Europe, as well as the differences between centralized and federally organized national political systems. The European Union further introduces a supranational level in Europe, which adds a multitude of translating and editing processes at the national and organizational levels.

Due to this heterogeneity, our network is shaped by lively debates and frequent disagreements. However, our debates emphasize, at the same time, complementarities and combinations between different approaches and research designs as opposed to highlighting disagreements between various schools of thought on directions in neo-institutionalism. In terms of theory, neither the societal macro level can be derived from 
local interactions, nor are the latter completely determined by the former. This micro-macro linkage also has implications for the neo-institutional analysis of organizations, as organizations are embedded within broader societal structures and are at the same time characterized by micro-social processes. The same applies to the methodological approaches that do not conform to any one particular school of thought but often realize their full potential in combination. In this regard, there may well be disagreements about appropriate theoretical and methodological approaches between the North American debates and a European standpoint. From our European perspective the North American discussions often tend to be fairly rigid and antagonistic.

\subsection{OVERVIEW OF THIS VOLUME}

In total, in this volume we present 15 further chapters including an afterword by John Meyer, which is intended to stimulate further discussions. The focus of most contributions is on how organizations and individuals handle heterogeneous and changing social conditions, which are subsequently reflected in various forms of change. It is worth emphasizing that much of the neo-institutionalism knowledge is now regarded as sedimented and institutionalized. Classical texts on the relationship between organizations and social environments, new approaches on institutional work, institutional entrepreneurs and institutional logics that often deviate from the original assumptions of neo-institutionalism, as well as John Meyer's macro-sociological and globalization theory, are all discussed both explicitly and implicitly in the chapters of this volume. Further, various connections are made between different approaches of neo-institutional thinking.

The chapters of this edited volume highlight three important points in regard to opportunities of theoretical, methodological and empirical combinations between North American and European lines of research traditions and their contributions towards the further development of institutional analysis. First, from a theoretical point of view, values that were somewhat neglected in the early cognitive-theoretical framework now play a vital role in neo-institutionalism. This shift is evident in our volume through the French conventions of worth theory (Boltanski and Thévenot, 2006) as well as the early institutionalism in American sociology (Selznick, 1957). Second, theoretical discussions pointing out the relevance of traditional sociological concepts such as 'unanticipated consequences of purposive social action' (Merton, 1936) as well as philosophical approaches such as 'process philosophy' (Rescher, 1996) for the institutional analysis 
are elaborated. Third, as highlighted above, methodologically case studies are of great importance in neo-institutionalism research. However, numerous other novel and innovative methodological approaches such as correspondence analysis, the analysis of visual artifacts using the example of logos and the analysis of websites and their connections are utilized in this volume. Detailed empirical examples from different European countries as well as relevant international studies analyzing a great variety of phenomena are presented; different forms of organization from all sectors (private, public, not-for-profit), including sector-spanning organizations, are in the focus of attention. In general, in the spirit of our network, we have tried to leave room for experimenting with different combinations of theoretical approaches, research methodologies and empirical cases, without providing a standard format to which all contributions need to adhere to. Based on the classical distinction by March (1991), the volume attempts to exploit proven research traditions and explore new possibilities. Below is a brief overview of the chapters.

In Chapter 2, Roger Friedland brings back the significance of values to the debate on institutional logics. He argues that without values, institutional theory neglects the 'why' - the purpose that drives humans and is core to the formation of societies. He argues that the loss of values in North American theorizing is related to the desire to leave behind the shadow of Parsons' theoretical architecture - a desire, we might say, European researchers never knew. Building on, but also departing from, an array of foundational thinkers from sociology, philosophy, and political science, Friedland lays out that institutional logics have a value grounding - an institutional substance that is enacted through practices around objects carried by subjects and categorized by names that this substance constitutes.

Christina Berg Johansen and Susanne Boch Waldorff explore the theoretical foundation and analytical contributions of the institutional logics perspective in Chapter 3. They identify two fundamental topics: (1) how institutional logics both guide and are guided by overarching institutional orders, and (2) how inter-logics relations create friction and space for change and agency. They use examples from different empirical papers to support and illustrate their investigation of these two topics. Further, they discuss how institutional logics contribute to institutional theory at large and inform our understanding of organizations in society.

In Chapter 4, Ann Westenholz explores the similarities and differences of the conventions and institutional logics perspectives in order to create a space for dialogue and mutual learning between the two approaches. Both approaches not only share a similar purpose, that is, helping us to understand indeterminacy and ambiguity, they also identify different 
social orders that may change over time. Both recognize that actorhood is important for the transformation of social orders, and they have both developed an understanding of how social orders and actorhood are interrelated. Despite these commonalities, the two perspectives have developed in different ways in France and the USA and not much dialogue has taken place between them until recently. Westenholz illustrates that a comparison of the two perspectives is helpful to create a common ground for analyzing and understanding how people coordinate their activities in indeterminate and ambiguous situations.

The study by Nadine Arnold and Birthe Soppe in Chapter 5 aims at thoroughly understanding the creation and institutionalization of what are called 'moral markets'. Arnold and Soppe examine the development of mundane commodities into morally value-laden products, which are culturally supported and demanded in the domain of mass markets. By analyzing a rich set of archival data on the history of fair trade in Switzerland over three decades, they trace the early beginnings, development, and mainstreaming of products that are imported from developing countries and sold at a price premium to guarantee the producers a decent remuneration. In their analysis, they show that the institutionalization of fair trade is the outcome of a valuation process, which is characterized by changes in product-level valuation practices and also by an increase in the blending of moral and economic values. Their contribution provides important implications with regard to the role of values and valuation in institutionalization processes.

The focus of Chapter 6 by Silviya Svejenova and José Luis Alvarez is on the proliferation of top management positions, the so-called 'C-Suite' in business firms. In a neo-institutional vein, the increase in the number of such positions is linked to the broader institutional environments in which business firms are embedded. However, according to the authors the above linkage does not automatically trigger a 'taken-for-granted' response by which new chief officer roles come into organizational life. Instead, such roles are actively constructed by strategically operating organizations in response to the institutional complexity that is increasingly characterized by competing and at times conflicting logics.

Stephan Bohn and Peter Walgenbach in Chapter 7 address institutional complexity and organizational strategies dealing with conflicting institutional demands. Using a politically highly sensitive case - nuclear power - and analyzing media articles over a 15 -year period, they draw attention to the contradicting and dynamic nature of the multiple institutional demands that organizations have to cope with. They show how German atomic power plant organizations played off different contradicting demands against each other, thereby negotiating the requirements with 
institutional stakeholders. This not only presents organizations as active agents in defining institutional demands, it also stresses that such demands are interwoven with broader political issues (in their case, climate change, safety of nuclear power, states' dependence/independence from politically unstable regions, etc.) and can be highly controversial and dynamic.

In Chapter 8, Markus Höllerer, Renate Meyer, and Michael Lounsbury focus on annual reports of Austrian publicly listed firms and analyze how corporations theorize their social and societal responsibilities. They describe the pattern that they find on the field level as politicization of corporations at the expense of a de-politicization of society: firms increasingly engage as 'citizens' in social policy while, at the same time, power and responsibility are relocated from the sphere of the neo-corporatist state to rather independently operating units such as private sector firms. The chapter not only addresses important conceptual and comparative issues in neo-institutional analysis, but it also speaks to research communities in macro-sociology, political science, and political economy that have not been at the center of attention of our approach so far.

Gili Drori, Achim Oberg, and Giuseppe Delmestri set out in Chapter 9 to identify historical trends in field-level processes of global world culture in individual organizational artifacts - university emblems. Their innovative methodology allows them to reconstruct and understand broad cultural trends and long historical changes in higher education through small, organizational-level visual icons. In addition, by tracing distributions and developments, they are able to identify period-specific cultural models and locate the individual universities within them. With their longitudinal study they add to the core concerns of institutional theory: the theory of fields, organizational roles and identities, world society theory, and to the visual and material turn in institutional analysis. In particular, they embed 'strategic' decisions by individual organizations in cultural and global dynamics of the organizational field, thereby institutionally 'grounding' their agency.

In Chapter 10, Marco Bottura, Raffaele Corrado, Bernard Forgues, and Vincenza Odorici focus on the issue of field-level change by discussing the transformation of the Italian wine industry. Conceptually, apart from different strands of institutional thought, they make particular use of the sociology of professions and the concept of boundary objects in the social studies of science and technology. By applying network analysis, they show the emergence of a new field structure where experts, consultants, ratings and rankings increasingly shape the field. Professional winemakers are of outstanding importance here, as they spread their expert knowledge throughout the network and connect wineries and, ultimately, their products in a hitherto unknown way. 
Carmelo Mazza and Jesper Strandgaard Pedersen explore in Chapter 11 the role of timing for field configuring events. In particular, they explore how big cities lately adopting the practice of international film festivals differ in the way they enact the vision of an international film festival with contents and practices primarily stemming from institutionalized standards. In their study of two festivals in two geographically and socially distinct contexts, Italy and its capital city Rome, and Denmark and its capital city Copenhagen, they show that time seems to be a factor that increases the variety of practices within a field. Contrary to conventional wisdom in institutional theory, late adopters may bring ideas of innovation and different practices, rather than producing homogeneity in field configuration processes.

In Chapter 12, Walter Powell, Achim Oberg, Valeska Korff, Carrie Oelberger, and Karina Kloos deal with the processes and mechanisms of organizational change and field transformation. On the one hand, this is a classical topic of neo-institutional theory and research, and the authors make use of an impressive array of knowledge from previous studies here. On the other hand, and based on that 'intellectual history' as the authors call it, they conduct a highly innovative study by focusing on new organizational forms and field transformation in the non-profit sector. To underline innovativeness, the authors have developed a web crawler in order to determine change by analyzing organizations' websites and their references to other organizations through hyperlinks. By doing so, they identify the diversity and dynamics of organizational fields whose boundaries are becoming increasingly porous.

In Chapter 13, Thomas Klatetzki aims at explaining the practice of lynching with the help of institutional theory. His chapter starts with the description of a lynching event in Tláhuac (a borough of Mexico City) that forms a base to discuss the constitutive role of violence for social orders. His key argument is that the institution of punishment enables a group of vigilantes to organize and implement violent action and that, in the course of this process, violence generates social solidarity. Central in his chapter is the idea of 'vigilante lynching as a distributed punishment script'. Klatetzki concludes with some brief comments on the regulative pillar of institutionalist organizational theory.

In Chapter 14, Mikołaj Pawlak and Adriana Mica connect the insights from the traditional sociology of unintended consequences with more recent developments in institutional theory. For the authors, the discussions on institutional work are of particular relevance here. Both individuals and organizations frequently generate unintended consequences as a result of their institutional work. In their stimulating conceptual paper, Pawlak and Mica not only distinguish different types of unintended consequences 
within a neo-institutional framework, they also identify a variety of coping mechanisms related to unintended consequences that result from different outcomes of institutional work. Interestingly, not only success or failure is discussed as an outcome, but also institutional compromise, institutional mid-course shift, and constant reinstitutionalization.

Chapter 15 by Elke Weik provides an innovative theoretical take on institutional substances as 'living forms'. Weik draws on a variety of philosophical traditions on substances, essences, and forms, and understands institutional substances as dynamic and active, striving for selfpreservation and reproduction, thereby stressing the agency of institutions themselves. This processual and agentic but ephemeral nature of substances is captured in the grammatical metaphor of the 'adverb', since institutions are ways of seeing, thinking, and feeling about things rather than things themselves. To avoid reifying institutions, Weik understands them as 'events' and 'experiences' with an affective and embodied impact that goes beyond rationalized cognition. She wraps up the chapter with an appeal for methodological approaches to institutions that refrain from claiming mastery over its object, borrowing from Goethe's idea of 'delicate empirics' and Shotter's concept of 'with-ness' thinking to achieve genuine understanding instead of explanation.

The final chapter, Chapter 16, by John Meyer makes clear the long trajectory neo-institutional research and theory has taken, from the initial formulations and seminal papers in the late 1970s and early 1980s to our current selection of papers in this volume. Classical texts focus squarely on the embeddedness of organizations in broader societal environments and analyze these linkages, while focusing less explicitly on the inner side of organizations. This inner side, organizations' internal differentiation, contradictions, and conflicts as well as the activities and orientations of individual and organizational actors come to the forefront in our book. In addition, Meyer's chapter makes clear that we need a broader historical perspective in order to take the current organizational forms and the unprecedented rise of organizations in the modern, globalized, and (neo-) liberal era into account. The unquestioned verities of this (modern) era have to be seen as socio-historical constructs that evolved over time and that are increasingly questioned now and, therefore, might look different in the future.

The network for organizational institutionalism in Europe has benefited from the commitment of many scholars and their willingness to share - in the spirit of the workshop - not only results from fully developed research projects, but also very early ideas. Only a few of these projects and ideas are represented in this volume. We wish to thank all authors for pushing our joint project further and for their distinct contributions. 


\section{REFERENCES}

Boltanski, L. and L. Thévenot (2006), On Justification: Economies of Worth, Princeton, NJ: Princeton University Press.

Czarniawska, B. and G. Sevón (eds) (2003), The Northern Lights: Organization Theory in Scandinavia, Copenhagen: Copenhagen Business School Press.

Hasse, R. and G. Krücken (2008), 'Systems theory, societal contexts, and organizational heterogeneity', in R. Greenwood, C. Oliver, R. Suddaby and K. Sahlin (eds), The SAGE Handbook of Organizational Institutionalism, Thousand Oaks, CA: SAGE, pp. 539-59.

Lounsbury, M. and C. Beckman (2015), 'Celebrating organization theory', Journal of Management Studies, 52(2), 288-308.

March, J.G. (1991), 'Exploration and exploitation in organizational learning', Organization Science, 2(1), 71-87.

Merton, R.K. (1936), 'The unanticipated consequences of purposive social action', American Sociological Review, 1(6), 894-904.

Meyer, R.E. (2008), 'New sociology of knowledge: Historical legacy and contributions to current debates in institutional research', in R. Greenwood, C. Oliver, R. Suddaby and K. Sahlin (eds), The SAGE Handbook of Organizational Institutionalism, Thousand Oaks, CA: SAGE, pp. 519-38.

Rescher, N. (1996), Process Metaphysics, New York: State University of New York Press.

Selznick, P. (1957), Leadership in Administration. A Sociological Interpretation, New York: Harper \& Row. 